\title{
Estimates of the Carbon Impacts of Commute Travel Restrictions due to COVID-19 in the UK
}

\author{
Kadambari Lokesh ${ }^{1}$ (D), Greg Marsden ${ }^{1}$ (D) \\ ${ }^{1}$ School of Environment, Institute for Transport Studies, University of Leeds \\ Keywords: commuting, carbon, covid-19, pandemic, mobile phone data \\ https://doi.org/10.32866/001c.21574
}

Findings

This paper explores the carbon impacts of the reductions in commute travel which resulted from restrictions placed on the general population in the UK. The article uses anonymised and aggregated mobile data for the period February 2020 to June 2020 to understand how commute trips changed spatially. This has been linked to journey length and emissions data to produce estimates of the consequent reductions in $\mathrm{CO}_{2}$ (an average range of 17-60\%). At a local level, the key factors that contributed to substantial $\mathrm{CO}_{2}$ reductions were high car ownership, paired with the prevalence of specific industrial employment types that could readily transition from a desk-based work to virtual working.

\section{Questions}

This paper explores the carbon impacts of the travel restrictions placed on the general population in the UK as a result of Covid-19 pandemic. Specifically, it focusses on commute journeys where the advice from the Government was to work from home, if possible (GOV.UK 2020). The article uses anonymised and aggregated data from O2, a major mobile network provider, between Feb-2020 to Jun-2020 to understand how commute trips fluctuated. This is of relevance to the broader climate crisis which requires deep cuts in emissions from significant demand reduction measures over the next two decades (Brand, Anable, and Morton 2019). Our research question is:

What impact did the COVID-19 "work from home if you can" policy bave on the commute patterns and $\mathrm{CO}_{2}$ emissions?

\section{Methods}

Anonymised and aggregated mobile data insights for Feb-2020 to Jun-2020, from $\mathrm{O} 2$ mobile, was used to evaluate the spatial variations in commute journeys. O2 connects with 23 million devices in the UK (25\% market-share) ${ }^{1}$ offering movement insights, when connecting with the mobile network. Daily estimates of numbers of commute journeys were provided for each of 375 Local Authority Districts (LADs) based on analysis of the durations of phone locations away from home which matched a commute pattern. ${ }^{2}$ Analysis of monthly commute data from the National Travel Survey [NTS0504] shows

\footnotetext{
1 The trip data used in this study covers changes implied by only the $\mathrm{N}$ of 23 million devices that connect to the $\mathrm{O} 2$ network and not the entire population

2 Commutes are estimated from regular home and non-home pairings with extended durations. A minimum of 10 people moving between an OD-pair is required to classify as a commute journey, to protect the anonymity of users.
} 
that the number of commute trips per day in Feb-2020 was similar to other months in the dataset, prior to the lockdown (Office of National Statistics 2020b). Therefore, the data for February was treated as the "pre-lockdown" baseline. Lockdown began on $23^{\text {rd }} \mathrm{March}^{3}$ in the UK and so April to June were considered "during-lockdown".

To convert journey reductions into a $\mathrm{CO}_{2} \mathrm{eq}$, it was necessary to assign estimates of journey length (by region) and mode split to each local authority. The NTS data, however, allows for differentiation at a regional level and only for pre-lockdown scenario. Similar data was sourced from the Scottish Transport Statistics (Transport Scotland Analytical Services 2018), Welsh Travel statistics (Welsh Government Statistics and Research 2019) and the Northern Ireland Transport Statistics (Northern Ireland Statistics and Research Agency 2020) for UK-wide coverage. Regional figures, assigned to the local authorities, within that region, are shown in Table 1.

There are a few shortcomings to the data and assumptions we have adopted. It is neither possible to estimate the actual monthly mode share reductions for commute, over the lockdown period, nor is it, to determine the extent to which the public transport (PT) levels reduced, by month and locality. We have attempted to allow for the impacts of these uncertainties through a scenario analysis described further below. Other factors such as increased unemployment or people being furloughed were excluded and so the estimates must be seen as upper bounds of $\mathrm{CO}_{2}$ reduction.

The district-level mobile data was first normalised to each of the 375 districts using the population estimates from UK census (Office for National Statistics, National Records of Scotland, and Northern Ireland Statistics and Research Agency 2017). The districts were then grouped into the NTS-geographic regions (shown in Table 1 ) and the commute journeys were differentiated into the NTS-modal shares. Upon splitting the trips, two other parameters were factored into commute $\mathrm{CO}_{2}$ estimation (Figure 1): the average trip lengths by $\mathrm{car} /$ other modes and modal emission factors.

Monthly commute $\mathrm{CO}_{2}$ emissions were estimated for each of the local authorities across the UK, between Feb-2020 and Jun-2020. February emissions were set as reference and the monthly percentage changes in $\mathrm{CO}_{2}$ emissions, between Apr-2020 and Jun-2020, were estimated for "during lockdown".

To deal with the uncertainties in the estimated emissions, a $2 \times 2$ matrix was created which allows for variations in the commute mode shares and the amount of public transport that may have operated, before and after the

\footnotetext{
3 A majority of the LADs (roughly $60 \%$ of the 375 LADs) have shown a relative spike in commute trips in the first two weeks of the March 2020 (supplemented by higher no. of working days), compared to their daily estimated equivalents in February 2020 (baseline month) (please see figure 2) .
} 
Table 1: Percentage mode share for commute journeys only (pre-lockdown), average trip lengths and $\mathrm{CO}_{2}$ emission factors

\begin{tabular}{|c|c|c|c|c|c|c|}
\hline \multirow{2}{*}{ Region of workplace $^{1}$} & \multicolumn{5}{|c|}{ Commute Modal split (\%) ${ }^{2}$} & \multirow[b]{2}{*}{$\begin{array}{l}\text { Average trip length } \\
\text { by car (miles) }\end{array}$} \\
\hline & Car & Bicycle & $\begin{array}{l}\text { Bus / } \\
\text { coach }\end{array}$ & $\begin{array}{l}\text { All } \\
\text { rail }\end{array}$ & Walk & \\
\hline North East & 78 & 2 & 6 & 3 & 9 & 9 \\
\hline Tyne and Wear & 73 & 3 & 10 & 6 & 7 & - \\
\hline Rest of North East & 83 & 0 & 3 & 4 & 11 & - \\
\hline North West & 76 & 2 & 7 & 4 & 9 & 8 \\
\hline Greater Manchester & 71 & 3 & 9 & 7 & 9 & - \\
\hline Merseyside & 71 & 2 & 9 & 5 & 11 & - \\
\hline Rest of North West & 82 & 2 & 4 & 2 & 9 & - \\
\hline Yorkshire and The Humber & 75 & 4 & 7 & 3 & 10 & 7.5 \\
\hline South Yorkshire & 74 & 3 & 8 & 0 & 11 & - \\
\hline West Yorkshire & 75 & 2 & 8 & 4 & 8 & - \\
\hline Rest of Yorkshire and The Humber & 74 & 7 & 5 & 0 & 12 & - \\
\hline East Midlands & 79 & 3 & 4 & 1 & 11 & 10 \\
\hline West Midlands & 80 & 2 & 6 & 3 & 8 & 8 \\
\hline West Midlands (met. county) & 75 & 1 & 10 & 5 & 8 & - \\
\hline Rest of West Midlands & 85 & 2 & 2 & 0 & 9 & - \\
\hline East of England & 78 & 4 & 3 & 3 & 10 & 12 \\
\hline London & 27 & 5 & 12 & 46 & 9 & 7 \\
\hline Central London & 8 & 5 & 7 & 71 & 6 & - \\
\hline Rest of Inner London & 20 & 5 & 14 & 47 & 11 & - \\
\hline Outer London & 55 & 3 & 16 & 15 & 10 & - \\
\hline South East & 74 & 4 & 5 & 5 & 11 & 11 \\
\hline South West & 75 & 4 & 4 & 2 & 13 & 8 \\
\hline England & 67 & 4 & 7 & 11 & 10 & - \\
\hline Wales $^{4}$ & 80 & 3 & 4 & 3 & 9 & 9 \\
\hline Scotland 5 & 70 & 3 & 9 & 5 & 11 & 12 \\
\hline Northern Ireland ${ }^{6}$ & 74 & 1 & 3 & 2 & 20 & 11 \\
\hline Great Britain & 68 & 3 & 7 & 7.8 & 10 & - \\
\hline Average trip length by mode ${ }^{7}$ (miles) & $\begin{array}{l}\text { Please see } \\
\text { column } 3\end{array}$ & 3.3 & 5.1 & 32.3 & 0.7 & - \\
\hline $\begin{array}{l}\text { Average Carbon Factors by mode } \\
\left(\mathrm{gCO}_{2} \text { eq/passenger } \mathrm{km}\right)\end{array}$ & 148.2 & 0 & 25.1 & 12.7 & 0 & - \\
\hline
\end{tabular}

\section{Notes}

${ }^{1}$ This excludes all those in employment that live in Great Britain but work outside of it and includes all those in employment that live in Northern Ireland and work in Great Britain.

${ }^{2}$ Source: Labour Force survey, “Statistical Dataset: Modal Comparisons (TSGB01)” 2019 [Table: TSGB0109]

${ }^{3}$ Refers to average trip length by car only. Source: Average Trip Length by region and purpose, Office of National Statistics 2020b [Table: NTS9912]

${ }^{4}$ Source: Welsh Government Statistics and Research 2019

${ }^{5}$ Source: Transport Scotland Analytical Services 2018

${ }^{6}$ Source: Northern Ireland Statistics and Research Agency 2020

${ }^{7}$ Refers to Average trip lengths for commute by modes other than by car; Source: Labour force survey ("Statistical Dataset: Modal Comparisons (TSGB01)" 2019) [Table: TSGB0103]

${ }^{8}$ Source: UK Government GHG conversion factors for passenger vehicles (Department for Environment, Food and Rural Affairs 2020) 


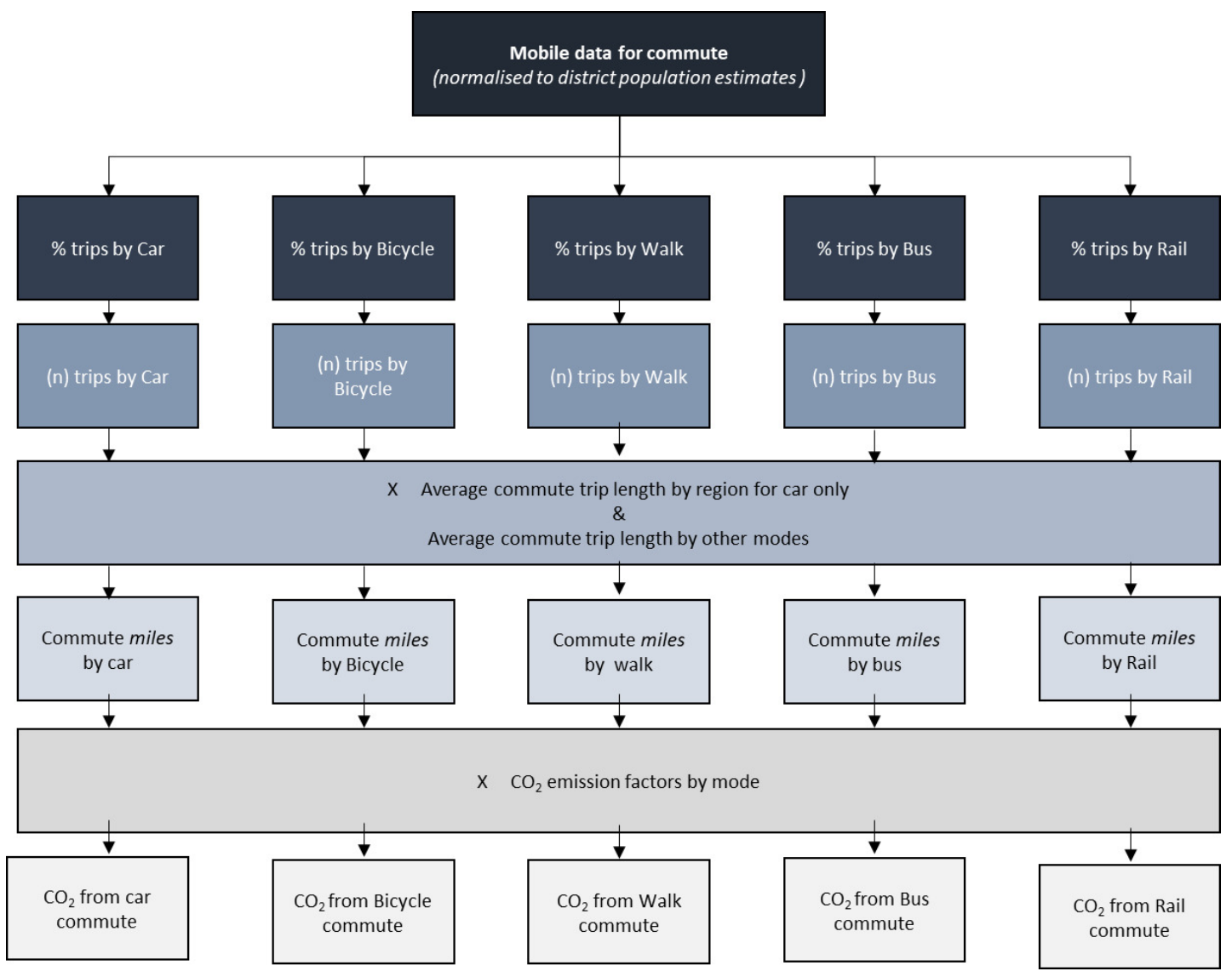

Figure 1: Approach for the estimation of $\mathrm{CO}_{2}$ emissions by mode for commute trips

lockdown. For clarity, the two mode share assumptions were: Scenario-a: "Prelockdown" mode share pattern retained; Scenario-b: "During-lockdown" estimated mode share patterns (details in "Notes and Assumptions" in Table 2). Considering the potential for emissions from PT, it is assumed that the emissions from commuters who usually travelled by PT (in "pre-lockdown" settings) would be saved "during-lockdown" as the services reduced (Scenarioc). Alternatively, Scenario-d included emissions assuming that services may still have operated "during-lockdown".

\section{Findings}

The anticipated baseline emissions determined for February 2020 (before lockdown) within this study, was $1422 \mathrm{kT} \mathrm{CO}_{2}$. A validation of our baseline monthly commute $\mathrm{CO}_{2}$ emissions estimate for February, against another national estimate for monthly commute emissions, is within $5 \% .{ }^{4}$ Overall, the range of emissions, reported in this sensitivity analysis, correspond to just 30-38\% of an equivalent 3-monthly pre-lockdown baseline emissions (1422kT estimated from February figures). Relative to overall magnitude of the

\footnotetext{
4 These estimates were drawn from averaging the daily emissions relative to their equivalent in Feb-2020. our $\mathrm{CO}_{2}$ estimates could be validated through a comparison with publicly reported figures for commute emission. It is estimated that the UK's annual commute carbon amounts to 18 billion $\mathrm{kgCO}_{2}$ eq, which breaks down to roughly $1500 \mathrm{kTCO}_{2}$ eq per month (Mobilityways 2021)
} 
Table 2: Estimation of monthly $\mathrm{CO}_{2}$ emissions applying "pre-lockdown" and "during-lockdown" modal distribution, followed by a sensitivity study encompassing the impacts of modal shares variations and fluctuations in public transport services and usage

\begin{tabular}{|c|c|c|c|c|c|c|c|}
\hline \multicolumn{2}{|c|}{ Parameters } & \multicolumn{3}{|c|}{$\begin{array}{l}\text { Scenario-a: "Pre-lockdown" mode- } \\
\text { share settings }{ }^{1}\end{array}$} & \multicolumn{3}{|c|}{$\begin{array}{l}\text { Scenario-b: "During-lockdown" mode } \\
\text { share settings }\end{array}$} \\
\hline & Mode of travel & Car & Bus & Rail & Car & Bus & Rail \\
\hline \multicolumn{2}{|c|}{$\begin{array}{r}\text { Emission factors }\left(\mathrm{gCO}_{2} \mathrm{eq} / \text { passenger } \mathrm{km}\right. \\
\text { travelled) }\end{array}$} & 148.3 & 25.1 & 12.7 & 148.3 & 25.1 & 12.7 \\
\hline & $\begin{array}{r}\mathrm{CO}_{2} \text { emission (Feb) } \\
\text { (baseline) (kT) }\end{array}$ & 388.9 & 56.8 & 22.3 & - & - & - \\
\hline & $\begin{array}{l}\mathrm{CO}_{2} \text { emission } \\
(\mathrm{Mar})^{3}(\mathrm{kT})\end{array}$ & 363.7 & 3.5 & 15.9 & 420.2 & 1.9 & 4.3 \\
\hline \multirow{3}{*}{$\begin{array}{c}\text { Monthly } \\
\text { commute } \\
\mathrm{CO}_{2} \mathrm{eq} \\
\text { estimate }^{6}\end{array}$} & $\mathrm{CO}_{2}$ emission (Apr) (kT) & 95.6 & 0.91 & 4.16 & 110.4 & 0.5 & 1.1 \\
\hline & $\begin{array}{r}\mathrm{CO}_{2} \text { emission (May) } \\
(\mathrm{kT})\end{array}$ & 137.5 & 1.31 & 6.0 & 158.9 & 0.70 & 1.6 \\
\hline & $\mathrm{CO}_{2}$ emission (Jun) (kT) & 168.5 & 1.60 & 7.3 & 194.7 & 0.9 & 1.8 \\
\hline & 3- months total (kT) & 401.6 & 3.8 & 17.5 & 463.9 & 2.0 & 4.7 \\
\hline \multicolumn{2}{|c|}{$\begin{array}{r}\text { Scenario c: 3-month total for all modes if PT } \\
\text { emissions saved (kT) }\end{array}$} & \multicolumn{3}{|c|}{422.9} & \multicolumn{3}{|c|}{470.7} \\
\hline \multicolumn{2}{|c|}{$\begin{array}{r}\text { Scenario-d: 3-month total for all modes no PT } \\
\text { emissions saved (kT) }\end{array}$} & \multicolumn{3}{|c|}{$480.7^{4}$} & \multicolumn{3}{|c|}{$543^{5}$} \\
\hline
\end{tabular}

\section{Notes and Assumptions for the scenarios}

${ }^{1}$ Mode shares were assumed to be in line with the pre-lockdown modal split of $68 \%$ for cars; $7 \%$ for buses; $10 \%$ for rail and $15 \%$ for other modes (Please see Table 1) (motorised travel make up $85 \%$ of total commute mode distribution; at $100 \%$, the split will be $80 \%$ for cars, $8.23 \%$ for buses and $11.8 \%$ for rail;)

2 "During-lockdown" commute trips were acquired by applying DfTs (March-June) average mode reductions ( $57 \%$ for cars; 80\% for buses and $90 \%$ for rail); motorised commute modes - Car: from $80 \%$ to $92.4 \%$; Bus: from $8.23 \%$ to $4.4 \%$; rail: from $11.8 \%$ to $3.1 \%$ )

${ }^{3}$ March commute estimates ( $383 \mathrm{kT}$ and $426 \mathrm{kTCO}_{2} \mathrm{eq}$ ) were excluded from the 3 -month total estimates since the travel restrictions had not perfectly set in until the last week of the month ( $23^{\text {rd }}$ March) leading for these $\mathrm{CO}_{2}$ estimates to be misleading for our assumed scenarios.

${ }^{4}$ Emissions in scenario (a-d) represents 3-month total $\mathrm{CO}_{2}$ emissions for all modes, in the "pre-lockdown" setting, taking into account the baseline PT emissions (Feb), allowing for the assumption that all PT services were operational, despite the fall in PT commute.

5 Emissions in scenario (b-d) represents 3-month total $\mathrm{CO}_{2}$ emissions for all modes, from the "during lockdown" commute setting, taking into account the baseline PT emissions (Feb), following PT operations mentioned in point 4.

${ }^{6}$ Working days and School/National Holidays in 2020 by month: February (20, 5) March (23, 3), April (22, 7), May (21, 10), June (22, 4)

reduction, the impact of mode share variations between the scenarios are relatively small. Assuming the mode share to be more car-oriented in lockdown, in line with national average mode use, estimates results in emissions which are $47.8 \mathrm{kT}$ to $62.3 \mathrm{kT}$ higher over the three months (or $3.4 \%$ - $4.4 \%$ of the anticipated baseline). Whether or not reductions in public transport translated into savings in public transport emissions, made a difference of $57.8-72 \mathrm{kT}$ or $4-5 \%$ of the anticipated baseline.

Figure 2 represents the monthly fluctuations in district-level emissions of commute carbon (representing scenario pair a-d), for Mar-2020 to Jun-2020. Commute traffic increased in the starting weeks of March than normal (20-25\%) which is most likely to be in preparation for the looming lockdown. A sharp drop then occurred from precautionary local closures of businesses, in advance of the 23rd March lockdown. However, the highest levels of commute carbon reduction, were observed in May 2020, in the range of - 40 to $-78 \%$. Applying a scaling factor based on the number of workdays to account for 

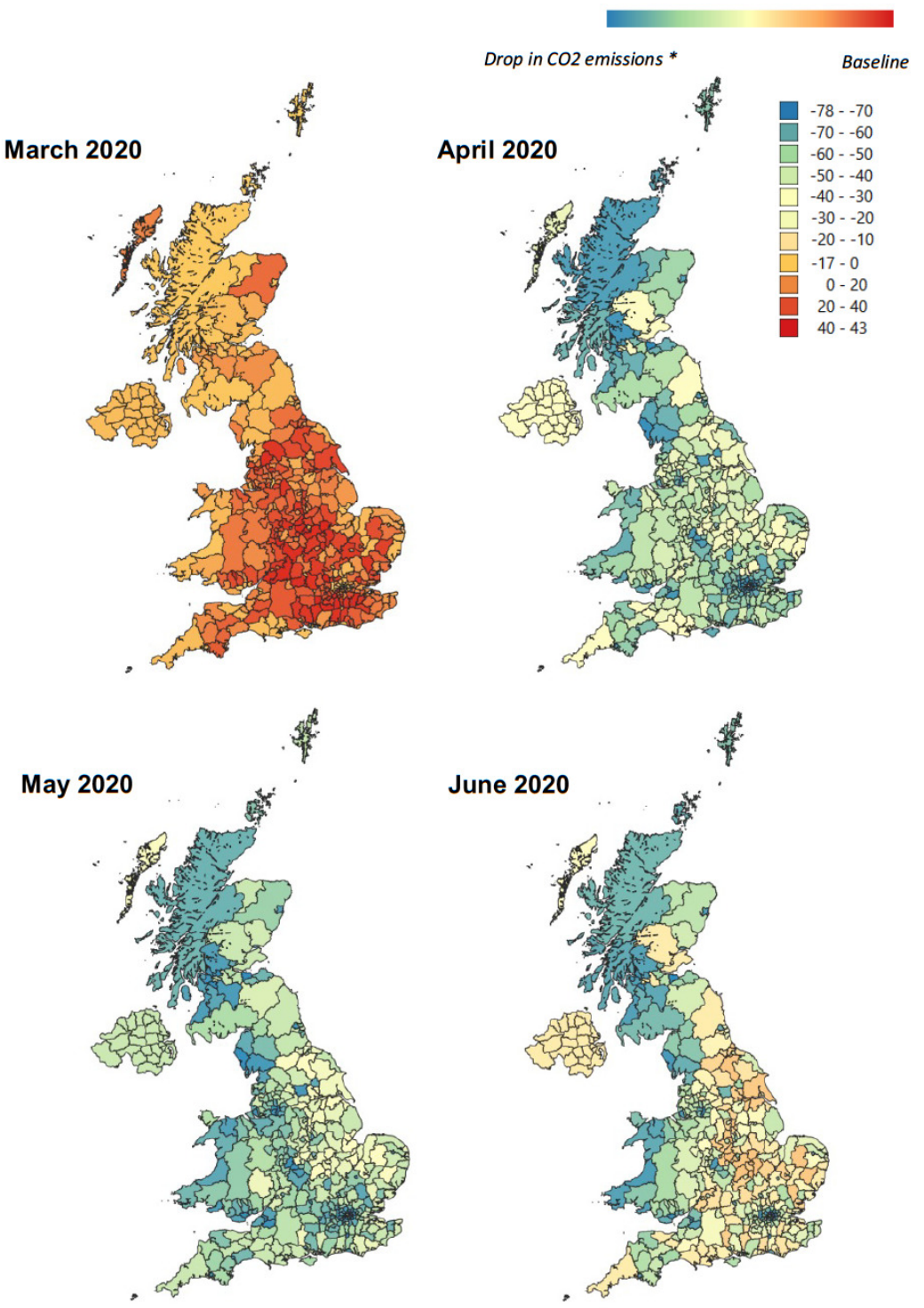

Figure 2: $\mathrm{CO}_{2}$ changes from variations in commute patterns across the UK (presented as percentage changes); Analysis period: Feb 2020- June 2020; $\mathrm{O}_{2}$ data for February used as baseline.

potential commute in a standard month, across March to June, led our calculated monthly commute emissions to be $\pm 5 \%$ that of our baseline estimates $\left(1500 \mathrm{kTCO}_{2} \mathrm{eq} /\right.$ month).

A matching of the travel adaptation and carbon reduction data was then made with district-level data on the density of certain industrial sectors that could successfully adapt to operate virtually and their associated car-ownership patterns. For this assessment, the 375 LADs were grouped into quintiles based on the percentage of commute emission reductions they demonstrated (Table 3). The openly available MOT (annual vehicle test) dataset ${ }^{5}$ was used to estimate the proportion of the car fleet held by households in each quintile 
Table 3: Comparison and analysis of contribution of car ownership and employment types on the overall commute carbon emissions within the different districts.

\begin{tabular}{|c|c|c|c|}
\hline Classification & $\begin{array}{c}\text { Percent } \mathrm{CO}_{2} \\
\text { reduction }\end{array}$ & $\begin{array}{c}\text { Proportion of UK } \\
\text { car fleet }{ }^{2}\end{array}$ & $\begin{array}{c}\text { Proportions of population in the specified type }{ }^{3} \text { of } \\
\text { employment and industry type }\end{array}$ \\
\hline Top Quintile & 68 to $78 \%$ & $38.4 \%$ & $40.3 \%$ \\
\hline $\begin{array}{c}\text { Second } \\
\text { Quintile }\end{array}$ & 56 to $67 \%$ & $21.8 \%$ & $23.4 \%$ \\
\hline Third Quintile & 37 to $50 \%$ & $16.9 \%$ & $16.1 \%$ \\
\hline $\begin{array}{c}\text { Fourth } \\
\text { Quintile }\end{array}$ & 24 to $34 \%$ & $13.8 \%$ & $12.7 \%$ \\
\hline $\begin{array}{c}\text { Lower } \\
\text { Quintile }\end{array}$ & 1 to $24 \%$ & $8.9 \%$ & $7.4 \%$ \\
\hline
\end{tabular}

Note:

${ }^{1}$ Corresponds to the classification of 375 districts into five Quintiles based on the percentage of district-level commute carbon reductions, observed over the analysis period.

${ }^{2}$ Source: Personal communication, 2019

${ }^{3}$ Corresponds to the total number of employed persons in technical, professional, associate professional roles within each quintile.

(Department for Transport 2020). As for employment type, the UK labour statistics demonstrated that of the $30-45 \%$ employed in professional, associate professional/ technical occupation, roughly $91.1 \%$ and $86.1 \%$ worked from home during the lockdown (Office of National Statistics 2020a). Sectors that followed this pattern also include information/ communication and scientific/ technical activities (of whom $79 \%$ and $45 \%$ worked remotely). Table 3 shows how the percentages of industry type compare across the quintiles.

The top 20\% districts for $\mathrm{CO}_{2}$ emission reduction (avg. of 68\% to 78\%) were those with the highest proportion of specific industry roles which could be worked from home and held the highest proportion of the UK fleet, thus reinforcing the effects of commute carbon reduction over the lockdown period (Table 3 ).

Future work should address the extent to which forced behavioural shifts can become embedded in the commute demand reduction and wider decarbonisation policies. There will be a need to explore what this means for different places, once a more nuanced understanding of the post-pandemic mode-shift behaviours begin to take shape.

\section{Acknowledgement}

This project has received funding from EPSRC under grant agreement EP/ S032002/1 and EP/R035288/1. This project has also received data courtesy of $\mathrm{O} 2$. The article is the responsibility of the authors and does not imply endorsement by the funders. 
Submitted: January 14, 2021 AEST, Accepted: April 07, 2021 AEST

This is an open-access article distributed under the terms of the Creative Commons Attribution 4.0 International License (CCBY-SA-4.0). View this license's legal deed at https://creativecommons.org/ licenses/by-sa/4.0 and legal code at https://creativecommons.org/licenses/by-sa/4.0/legalcode for more information. 


\section{REFERENCES}

Brand, Christian, Jillian Anable, and Craig Morton. 2019. "Lifestyle, Efficiency and Limits: Modelling Transport Energy and Emissions Using a Socio-Technical Approach.” Energy Efficiency 12 (1): 187-207. https://doi.org/10.1007/s12053-018-9678-9.

Department for Environment, Food and Rural Affairs. 2020. "Emission Factors Detailed by Source and Fuel - Defra, UK.” London: Department for Environment, Food and Rural Affairs (Defra). https://naei.beis.gov.uk/data/ef-all.

Department for Transport. 2020. "Anonymised MOT Tests and Results.” May 20, 2020. https://data.gov.uk/dataset/e3939ef8-30c7-4ca8-9c7c-ad9475cc9b2f/anonymised-mot-tests-andresults.

GOV.UK. 2020. "Staying at Home and Away from Others (Social Distancing).” GOV.UK. 2020. https://www.gov.uk/government/publications/full-guidance-on-staying-at-home-and-away-fromothers/full-guidance-on-staying-at-home-and-away-from-others.

Mobilityways. 2021. "Mobilityways - Zero Carbon Commuting."

https://www.mobilityways.co.uk/.

Northern Ireland Statistics and Research Agency. 2020. "Northern Ireland Transport Statistics 2019-2020.” Travel and Transport. Department for Infrastructure, Analysis,Statistics and Research Branch. http://www.infrastructure-ni.gov.uk/articles/northern-ireland-transport-statistics.

Office for National Statistics, National Records of Scotland, and Northern Ireland Statistics and Research Agency. 2017. “2011 Census Aggegate Data.” UK Data Service. https://doi.org/10.5257/ CENSUS/AGGREGATE-2011-2.

Office of National Statistics. 2020a. "Coronavirus and Homeworking in the UK - Office for National Statistics.” https://www.ons.gov.uk/employmentandlabourmarket/peopleinwork/ employmentandemployeetypes/bulletins/coronavirusandhomeworkingintheuk/april2020.

- - . 2020b. "When People Travel." GOV.UK. https://www.gov.uk/government/statistical-datasets/nts05-trips.

“Statistical Dataset: Modal Comparisons (TSGB01)." 2019. GOV.UK. 2019. https:/www.gov.uk/ government/statistical-data-sets/tsgb01-modal-comparisons.

Transport Scotland Analytical Services. 2018. "Scottish Transport Statistics.” Statistics Release 37. Scotland, UK: Transport Scotland.

Welsh Government Statistics and Research. 2019. "Welsh Transport Statistics: Road Traffic:2018.” Research and Statistics. Road Transport and Statistics. 2019. https://gov.wales/roadtraffic-2018-html\#section-30647. 